\title{
Dynamics of Academic Mobility: Hegemonic Internationalisation or Fluid Globalisation
}

\section{PETER SCOTT}

UCL Institute of Education, 20 Bedford Way, London WC1H 0AI, UK. E-mail: p. scott@ioe.ac.uk

Two broad frameworks are used to describe and analyse the mobility of academic staff. The first, and dominant, framework focuses on flows from the 'periphery' to the 'core', although that 'core' is also evolving (and is no longer dominated by North America and Western Europe but is increasingly likely to embrace dynamic East Asia systems). This first approach is labelled 'hegemonic internationalisation'. The second framework focuses instead on issues of development, the emergence of global communities and social movements. This is labelled 'fluid globalisation'. The article argues that the latter may be more useful for understanding trends in academic mobility.

\section{Introduction}

The sub-title of this article - 'hegemonic internationalisation or fluid globalisation?' reflects the considerable uncertainty that exists about the wider impact of the international flows of students and (especially) staff in higher education, and of the more general phenomenon of the internationalisation of the academic labour force. Which is the most informative label: brain drain, brain gain, brain circulation or something different? Should such flows be seen in terms of relations between 'peripheral' regions, located in the developing world, and 'metropolitan' centres, still located predominantly in North America, western Europe and Australasia (although the rise of east and south Asian economies - and, correspondingly, the power of their developing higher education systems - is rapidly shifting this balance)? In other words, is the internationalisation of the academic labour force not true internationalisation at all but an aspect of global inequality and the struggle for hegemony? Certainly, much of the language used by political and university leaders in the 'West', in which words such as 'competition' and 'rankings' frequently appear, tends to support this interpretation. ${ }^{1}$ Or should these flows 
of students and staff now be seen in the wider context of fluid and contested forms of globalisation that can no longer be regarded as simply an expression of the existing global order - military, economic, scientific and cultural? Other elements in the rhetoric used to describe, analyse and justify the internationalisation of the academic labour force, such as 'community', 'collegiality', 'aid, 'development' or 'empowerment', tend to support this second - and more generous - interpretation. ${ }^{2}$

These two broad interpretations have been expressed in bold headline terms rather than the more nuanced terms that are more appropriate, perhaps even to the extent of caricature. But my justification is that this approach may help to illuminate the doubts and ambiguities that are exposed in discussions of the significance of the internationalisation of the academic labour force. These doubts and ambiguities are present at every level - at the level of the programmes and policies of international organisations such as the World Bank, the Organisation for Economic Cooperation and Development (OECD) or the United Nations Educational, Cultural and Scientific Organisation (UNESCO); at the level of the programmes of regional blocs such as the European Union; at the level of the internationalisation strategies adopted by nation states; and at the level of the strategies of individual universities. This fault line between hegemonic internationalisation and fluid globalisation runs through them all.

After the introduction, this article is divided into four sections that attempt to illuminate this central theme, or dilemma:

(1) The first is an attempt to offer a brief statistical survey of trends in academic mobility. This is far from an easy task because of definitional differences and shortcomings in data collection, especially over consistent time series. These difficulties illustrate the complexity of flows in the international academic workforce. It has many strands - at different levels and over varying time periods. As a result, it may be misleading to consider academic mobility in the singular or in general.

(2) The second section offers a brief historical survey. Scholars and scientists have always been mobile; this is not a recent, late 20th or early 21 st-century phenomenon. It goes back to the earliest days of the university. Indeed, it may be that the proportion of scholars who were peripatetic and travelled around the universities of medieval Europe (and equivalent institutions in the Islamic world) may well have been greater than the proportion today.

(3) The third section considers the internationalisation of higher education in general, embracing a wide range of trends. These include the global flows of international students, transnational education, the emergence of international groupings (or 'clubs') of universities and also of regional blocs and, more broadly still, the drift towards more market forms of higher education with which internationalisation is closely, even symbiotically, linked. It is possible to broaden this discussion even more and to consider the impact on higher education of radical reconfigurations of time and space, i.e. new modes of 
teaching delivery exploiting the possibilities of 'virtuality', which include the development of massive online open courses (MOOCs), and also new modes of research and knowledge production.

(4) The fourth and final section extends this discussion of these radical configurations of time and space, centre and periphery, and considers the wider terrain of globalisation. It is important to recognise that the mobility of academic staff is just part of a wider picture, the emergence of new global (and highly mobile) elites and also the flight of the world's poor, as refugees and economic migrants, as global inequalities have increased. International flows of scholars and scientists cannot be considered in isolation from these wider patterns of global mobility, not least because it is in this context that nation states have developed their immigration policies, at once attractive (to rich bankers, distinguished scientists and young researchers, the future seed-corn of higher education and research systems) and repulsive (to low-value 'economic migrants', refugees and - perhaps - non-elite international students). It is also here that the fault line between hegemonic internationalisation and fluid globalisation is most prominent.

\section{Global Trends in Academic Mobility}

The overall scale of academic staff mobility is reasonably clear, in aggregate terms although this clarity is not derived from reliable time series of official statistics (because there are none of internationally mobile academics, although there are of internationally mobile students), ${ }^{3}$ the aggregate data that are available have been painstakingly (and often painfully) accumulated by individual researchers, which limits our ability to discern trends. Moreover, much of the fine-grain detail is absent. This makes it more difficult to discern the overall 'shape' of the internationalisation of the academic workforce, and how that overall 'shape' is changing. As a result, broadbrush speculation has had to substitute for rigorous analysis of reliable data.

In fact a number of key questions cannot be answered clearly and categorically - how many academic staff are working outside your home countries? When did they move - as members of migrant families (perhaps as children who were then assimilated into their new countries), as $\mathrm{PhD}$ students, as post docs or young researchers, or as mature scientists and scholars? Which countries are the most significant 'importers' of academic talent, and which are the biggest 'exporters'? And what trends can be observed? However, despite these difficulties, a serious attempt must be made to come to grips with the available dataand, in particular, to identify the lacunae in the data and, therefore, what can be confidently stated (and what cannot) before considering whether these flows can best be described as 'brain drain', 'brain gain', or 'brain circulation' in the overarching context of the tension between hegemonic internationalisation and fluid globalisation,

There are several reasons for this lack of reliable data.

- The first, and perhaps most significant, is that the movement of academic staff is covered, to the extent that it is covered at all, by employment and 
immigration rather than higher education statistics. Because, as has already been indicated, academic staff is not a homogeneous and monolithic category, different categories of academic staff are treated in different ways in employment and immigration statistics.

- A second reason, as has also already been indicated, is that trends in academic staff mobility have often been studied as a subsidiary topic in wider studies of the changing nature of the academic profession. As a result the available data tends to be episodic.

- A third reason is that formal rules about citizenship differ between countries, which produce distorting effects. For example, long-term residents may be regarded as 'international' staff in some countries. This is also sometimes the case with international students. For example, the United Kingdom includes international students in the total number of immigrants; other European countries do not. Also, although the ethnic origins of academic staff are recorded, there is no information available about their countries of origin.

- A fourth reason is that the free movement of all kinds of labour within the European Union has also made it more difficult to track the flows of academic staff within it, although this is probably the world region where such flows are most intense.

- A fifth reason is that there are no consistent definitions of academic staff (for example, are $\mathrm{PhD}$ candidates students or staff?), which means that data collection must begin with the construction of such definitions.

- A sixth reason, linked to the fifth, is that there cannot be a simple categorical distinction between 'international' and 'home' staff. For example, the determining factor may be the formal status of an individual (in other words, their passport), their own initial higher education or university that has awarded their doctorate (which will be different in the case of mobile students, who are most likely also to be mobile in their academic careers).

- A final reason is that national frontiers change with disturbing effects on the data. A Slovak professor in Prague is now 'international', as is an Armenian professor in Moscow or a Serbian in Kosovo.

There are further complications. But it should already be clear that the available data on academic mobility must be used with caution, especially if they are used to make crosscountry comparisons. However, three broad conclusions can be drawn from the data.

The first, although dwindling perhaps in importance as the 21 st century advances, is that geo-political considerations remain important.

- Countries that were once colonial powers (or achieved a similar quasiimperial global reach - notably the United States and the former Soviet Union) clearly have a heightened capacity to recruit 'international' staff.

- Also (and here there is clearly some overlap), countries that speak 'world' languages - English, French, Spanish - are also likely to attract 'international' staff. 
- A third 'geo-political' effect (and one that may have a contrary effect), is that there is a pronounced big-country small-country effect. It is much easier for a professor in the United States to build a successful academic career in her/his own country than, say, a professor from Latvia.

- A fourth such effect is that common cultural spaces make it easier for academic staff to be mobile. There is nothing remarkable about staff from Austria or (German-speaking) Switzerland working in Germany or staff of other Arab countries working in universities in Saudi Arabia or the Gulf states.

- A fifth consideration is that economic conditions play a key role - whether banking crises, differential growth rates or increasing global inequalities.

- Finally, of course, there are the political reactions to these changing economic conditions - for example, revolutions, civil wars or restrictions on immigration.

The second broad conclusion is that it is misleading to talk about a single domain, or market, when we are considering academic staff mobility. In fact there are several domains, or markets, with stronger or weaker connections between them.

- One is short-term mobility, such as staff exchanges or sabbaticals. Often this is not regarded as true mobility, but exchanges and out-of-country sabbaticals may have an important effect on fostering international understanding and inculcating a global outlook, especially if they are repeated.

- A second domain, or market, is mobility among PhD students and postdocs (and, therefore, among early-career researchers). As a result, international student mobility and academic mobility overlap.

- A third is the career-long resettlement by 'international' staff, which has many of the characteristics of permanent immigration. It is often this third domain, or market, that is regarded as the 'heart' of academic mobility.

- A fourth is the recruitment of globally mobile 'stars', senior professors with already established research reputations - a trend, of course, which has been greatly encouraged by the rise of global university league tables and the discourse of 'world-class' universities.

Clearly there are connections between these different domains of mobility - short-term exchanges can lead to permanent relocation, $\mathrm{PhD}$ students and early-career researchers stay on (often for personal and family reasons). But these connections are fluid. The dynamics of these distinct domains are all different - which can mean that aggregate data may not tell us much (even if the methodological problems are left to one side).

The third broad conclusion is that, despite all the qualifications and caveats about the reliability of the data, there is a consensus that the proportion of 'international' staff is increasing, that academic mobility is becoming a more pronounced characteristic of modern higher education systems. All the data point in this direction. For example, a major study of the academic profession in the United Kingdom published last year found that, in 2007-2008, 22\% of academic staff were from outside the UK and that the proportion of new staff appointed since that date who were from outside the UK had risen to $27 \%$. Data for other countries in this transnational study 
(ten other European countries were covered, plus others in the Far East and Latin America - and, of course, the United States) was consistent with this finding.

However, it is important to emphasise that this pattern of quantitative growth reveals very little about its drivers, the qualitative aspects of academic mobility. Is the proportion of 'international' staff increasing because of a lack of demand from 'home' applicants for academic posts (in other words, a powerful 'pull' factor) - or because of a lack of academic posts back home (a 'push' factor)? Is the increase in academic mobility evidence that world-class science and scholarship are being concentrated in a smaller number of countries - or of the internationalisation of modern higher education systems under the impact of globalisation (and what role is being played by marketisation)? All of these are probably significant factors - but in shifting and unstable combinations that are difficult to assess.

\section{Academic Mobility in Context}

The lack of reliable data on academic mobility and the inadequacy of the data that do exist as an explanatory tool are reasons for the difficulties experienced in determining the evolving 'shape' of academic mobility. But a more important reason is that academic mobility cannot be seen as an isolated and self-contained phenomenon. Instead it must be considered in a wider context, especially if the question posed in the title of this article - hegemonic internationalisation or fluid globalisation? - is to be addressed. Three aspects of this wider context will be considered.

- The first aspect is the historical dimension. There is a risk, perhaps a growing risk, of what is sometimes termed 'presentism' - in other words, treating contemporary trends and phenomena as entirely novel. This is rarely the case because 'there is (almost) nothing new under the sun'.

- The second aspect is the internationalisation of higher education as a whole. The (increasing?) mobility of academic staff is only part of a bigger picture dominated by large-scale flows of international students. To some degree academics can be regarded as a separate phenomenon; but in other respects as a subsidiary phenomenon.

- The third aspect is the impact of globalisation. The acceleration of the (voluntary) flows of highly mobile global elites has been accompanied by the (involuntary) movement of the world's dispossessed. Both are outcomes of the liberalisation (and marketisation) of the global economy. There have also been far-reaching political, social and cultural effects. So-called 'fundamentalism', which may take the form of violent resistance to secular forms of globalisation, and 'hybridisation', the creative mixture of global and local cultures, are just two examples.

\section{History of Academic Mobility}

Academic mobility is not a new phenomenon. To assert this is not necessary to invoke sentimental memories of scholars wandering around the universities of medieval 
Europe or Islamic philosophers migrating from Cordoba to Cairo - or even to remember the Puritan ministers who crossed the Atlantic to found Harvard College in colonial Massachusetts (and their many successors who travelled from London or Paris to establish new universities in Africa or Asia).

There are many more recent examples. In the late 19th century and the first quarter of the 20th century many scholars fled from the repression (and pogroms) of absolutist Europe to refresh universities in the west of the continent. This movement from the Pale to the Academy produced some famous scholars. During the same period, imperialism and colonialism triggered large flows of students and scholars, especially to and from France and the United Kingdom. ${ }^{4}$ In the second quarter of the last century the persecution of the Jews by the Nazis stimulated a similar flow not just to Western Europe but across the Atlantic to the United States. Without this infusion of academic talent it is difficult to explain the dynamism of post-war American science or the development of the research university and the growth of the multiversity, two institutional types that now dominate the global higher education landscape.

It is also worth remembering that leaders of liberation struggles in Africa and Asia also often found temporary refuges in universities from the 1930s through, in the case of apartheid South Africa, to the early 1990s. Although not perhaps an example of academic mobility (because that was not its primary motive), they often made significant contributions as scholars and teachers in the universities that offered them refuge - not least in the development of new and more radical subjects. This form of academic mobility remains important today, as refugee scholars continue to enrich the universities that have offered them refuge. After 1960, with the retreat from empire and the development of new states, the imperatives of development (and aid) stimulated new outward flows of academic talent - as well, of course, as reverse flows to Europe and the United States. The dismantling of Communist rule in Central and Eastern Europe had similar, although more muted, effects.

And now, with the development of more 'market' forms of higher education, new dynamics have entered the domain of academic mobility. ${ }^{5}$ The lessons to be derived from history are clear. It is important to consider academic mobility in the context of these successive waves, all with different origins but producing perhaps similar effects (at any rate, in increasing the proportion of 'international' staff). One has reinforced another. Current forms of academic mobility must be considered in the context of history not as a de novo phenomenon. ${ }^{6}$

\section{The Internationalisation of Higher Education}

The second context is the wider internationalisation of higher education. If the historical context offers a 'vertical' perspective on academic mobility (like the layers of an archaeological site), this second context offers a 'horizontal' perspective - laying academic mobility alongside other elements of internationalisation such as the flows of international students, the growth of transnational education, the rush to establish MOOCs, the increasing influence of global league tables and the development of new 
'knowledge' communities increasingly freed from the constraints of time and space. Although there are other important elements of this wider internationalisation of higher education, these three are arguably the most important.

\section{The Growth of International Education}

According to the latest figures from the OECD there are (or were in 2011, the most up-to-date figures available) 4.3 million students studying outside their home countries - more than double the number in 2000 (an annual growth rate of 7\%), and four times as many as there were in $1980 .^{7}$ Data from UNESCO paint a similar picture. ${ }^{8}$ All the predictions are that this growth will continue into the future - although the impact of the economic recession that has affected nearly all countries since 2008 and the rise of right-wing anti-immigration political parties may slow the rate of increase. But, whatever happens, this has been one of the most significant trends in modern higher education systems. Despite the obsessive focus on the United States as the magnet for international students, in fact it is Europe that is the top destination - $48 \%$ of all international students, as opposed to $21 \%$ in North America.

However, the impact of these massive flows of international students on academic mobility may not to be straightforward. There appears to have been both a general and a specific effect. The general effect is that, as universities (especially the major research universities) have become more international in their student bodies, so the employment of international academics has become more routine - even where there have been legal restrictions on such employment. The specific effect, of course, is that many international students, particularly those on $\mathrm{PhD}$ programmes, stay on, first, as young researchers and then established academics. In fact many countries - notably the United States and the United Kingdom but also many other western European countries - depend crucially on the employment of foreign-born staff to maintain their academic capacity, particularly in key scientific and engineering disciplines.

\section{Transnational Education}

Transnational education is often regarded as one of the most dynamic arenas of internationalisation, the 'wave of the future'. However, it is a complex and multi-faceted phenomenon. To see transnational education as the purest form of internationalisation through which universities are able to escape from national constraints and new forms of global provision can flourish may be misleading. There have been a number of trends that have impacted on academic mobility.

(1) One is the development of institutional partnerships across national frontiers, often with institutions in more 'peripheral' countries providing the initial stages of higher education that are then 'topped up' in their partners in 'metropolitan' (or 'core') countries. Of course, considerable care must be taken in defining which are 'peripheral' countries and which are 'metropolitan' (or 'core') in the context of contemporary higher education systems because these categories are 
rapidly changing. For example, Malaysia, Singapore or Korea can no longer be defined as 'peripheral' countries in this respect; indeed the two latter now possess among the world's most developed higher education systems to match their high levels of economic development. China and India, although with very different histories of (and approaches to) internationalisation, are also moving rapidly from the 'periphery' to the 'core'. These institutional partnerships tend to focus primarily on students. But they often embrace the upgrading of the credentials of academic staff, staff exchanges and other forms of academic mobility.

(2) A second trend is the development of branch campuses, sometimes building on these partnerships. The University of Nottingham in the UK, New York University in the United States and Monash University in Australia have been particularly active. The motives for establishing branch campuses are often complex. One motive is to show-case the 'brand' of the parent university; another is to enable students to have an 'international' experience while staying 'at home', crucially at lower cost; a third motive is to circumvent local restrictions of the work of 'foreign' universities. The development of branch campuses is closely linked to the liberalisation of higher education 'markets', giving greater freedom of action to private institutions (which can overcome local restrictions by partnering with public universities in other countries) as well as opening up local 'markets' to such institutions.

(3) The third, and most recent, trend is the development of MOOCs (massive open online courses). As well as further developing more 'virtual' approaches to student learning, MOOCs may also mark a further extension of the idea of the global market in higher education, by transcending national frontiers. In most cases the development of MOOCs has been undertaken by public universities and private companies, generally in the media industry, working together. As is the case with branch campuses, motives are mixed and various. They too help to show-case university 'brands', acting as 'taster' programmes that may encourage students to move onto more established programmes. They offer flexible packages of learning materials that can be accessed at low, or no, cost (although generally they do not lead to traditional academic awards). However, the impact of MOOCs may be as much local as global.

All three trends tend to accelerate academic mobility. Institutional partnerships stimulate staff exchanges that may lead to longer-term relocation. Branch campuses also promote mobility, in the opposite direction perhaps, as well as leading to a mixture of staff (the academic staff of branch campuses are usually drawn from several different countries). MOOCs, of course, will produce intense forms of 'virtual' staff mobility, as professors in the US (or Europe) 'teach' students based many thousands of miles away. 


\section{Global League Tables}

The third aspect of the internationalisation of higher education that deserves attention in terms of its impact on academic mobility is the (irresistible) rise of global university league tables. ${ }^{9}$ These league tables have been dismissed as superficial and trivial, simply an aspect of marketing and branding. But, however superficial and trivial, they are not inconsequential. Their rise has had far-reaching effects on national policies and institutional behaviour.

- The policies of many Governments are now heavily influenced by the desire to have more of their universities in the top 100 or top 500. For example, the Irish Government was urged by a group of external experts to merge Trinity College Dublin and University College Dublin principally on the grounds that Ireland could support only one 'worldclass' research university, a recommendation that thankfully was rejected. In some cases the desire to replace uniformity by differentiation, particularly with regard to research funding, may be driven as much by this desire as by the organic logistics of research.

- Institutional strategies and behaviours are also influenced by the desire to perform better in global league tables (or to be admitted to the more prestigious global university 'clubs'). These league tables promote academic mobility simply because one of the most important criteria is the proportion of international staff - the higher the proportion, the more highly ranked the university. So there is now a built-in incentive to recruit more international staff (which, of course, discriminates against universities in minority-language countries and flatters those in Anglophone - and, to a lesser extent, Francophone countries - or those where communication in 'Globlish' is widespread).

Whatever the merits of global league tables, they clearly have an important impact on academic mobility. The 'international' dimensions of higher education, in terms of student recruitment, the employment of academic staff and the production of internationally cited research, have become key determinants of status.

There are several other aspects of the internationalisation of higher education that impact on academic mobility. For example, the direct and indirect impacts of the Bologna process, and the development of the European Higher Education Area (EHEA), have tended to reduce barriers to academic mobility as European higher education systems have adopted increasingly congruent structures and policies. Not only have these initiatives directly supported academic mobility, albeit on a relatively small scale, by increasing the cohesion of European higher education, they have also created a more favourable climate for more intensive staff mobility. ${ }^{10}$

\section{Globalisation}

The third contextual element is the impact of globalisation in a wider sense. Much has been written on the theme of globalisation, predominantly in the context of global 
economic integration and liberalisation and to a lesser extent in terms of the emergence of global cultures. Some exciting links have been made to theories of 'fluid modernity'. ${ }^{11}$ Concepts of 'mobility', in the widest possible sense, have also been explored. ${ }^{12,13}$ Surprisingly, in the light of the central roles played by universities in the production of a highly skilled (and, as a result, more mobile) workforce and of scientific and technical knowledge and its reproduction of cultural forms, less attention has been paid to the links between the internationalisation of higher education and the wider phenomenon of globalisation. This section is not the place for an extended discussion of the reasons for this comparative neglect of the role universities play in globalisation, still less of globalisation in general. However, there are four dimensions of globalisation that appear to be relevant to academic mobility.

(1) The first, already alluded to, is the development of a global economy, accompanied by policies that are usually labelled 'liberalisation' (in other words, the reduction of protectionist barriers, more flexible labour markets and free movement of capital and labour - and often, as collateral damage, the erosion of welfare states based on high levels of public expenditure and also an increase in global inequality). The novelty of globalisation, viewed through this essentially economic lens, can be exaggerated - first, because integrated world markets have existed for many centuries and, secondly, because there are alternative and rival accounts of globalisation. Most significant perhaps are worldwide environmental and social movements, which have a particular resonance in universities both in terms of student attitudes and scientific research. But these alternatives and rivals also include various forms of resistance to economic (neo?) liberalism and market generated hegemonies;

(2) The second is the compression of time and space, mainly but not exclusively as a result in information and communication technologies. ${ }^{14}$ As a result 'virtual' neighbours can appear to be more real than 'physical' neighbours; new and disturbing notions of 'intimacy' have developed; and global digital communities have emerged. More concretely, new divisions of labour have also become possible - in terms of both material and intellectual production. This so-called 'digital revolution' has also led to the development of radically new communicative cultures and deeply affected social behaviour and the formation of individual identity, notably through the rise of so-called 'social networking'.

(3) The third dimension of globalisation that is relevant to academic mobility is the development of so-called 'hybrid' cultures that comprise, often in highly unstable combinations, aspects of so-called 'world' cultures - the global ideas, brands and images with which we are all familiar - and also aspects of local and traditional cultures. In negative terms these new cultures often have disturbing effects on the 
stability of social, and family, structures; in more positive terms they have reduced the social and cultural barriers to mobility as the result of the growth of global 'familiarity'.

(4) The fourth aspect of globalisation is the acceleration of all forms of mobility - from short-term tourism to long-term relocation, affecting both global elites (for example, in finance and banking - but maybe also in the academy) and the globally dispossessed (migrants and asylum seekers). Indeed, under conditions of globalisation it appears both the elites and the dispossessed are most mobile - leaving the middle ranks of society more fixed (and content perhaps with 'virtual' mobility or short-term visits). It is important to locate academic mobility, and large-scale flows of international students, in this wider context of accelerating mobility.

All these aspects of globalisation clearly have important implications for academic mobility. In one sense mobile academics can be regarded as 'rootless cosmopolitans' (or, more fairly, those who can most successfully navigate through the new 'hybrid' cultures). In another sense they can be viewed as just one element within the movement of global elites. In a third sense their mobility can be seen as the effect of increasing global inequality, as world-class science is concentrated more than ever in a small number of elite universities (which, as a result, makes their credentials even more attractive). In all these senses academic mobility is implicated in the dilemma set out in the title of this article - hegemonic internationalisation or fluid globalisation?

\section{Conclusion: Hegemonic Internationalisation or Fluid Globalisation?}

The question posed in the title to this article, of course, offers a too stark and therefore contrived choice. Its value is that it tries to capture something of the quality of the debate about how the gathering pace of academic mobility in 21st-century higher education should be interpreted - as further evidence of the hierarchy, and hegemonies, that have always prevailed in the political (and perhaps scientific and cultural) world-orders; or of the transformation of this hierarchy and hegemonies into something different, which may be difficult to describe in detail but reflects the more open and fluid qualities of globalisation. One way to analyse this, admittedly artificial, choice is to ask whether academic mobility is best characterised in terms of (predominantly) brain drain, brain gain, or brain circulation or whether these labels are themselves too limited to capture the heterogeneity of this phenomenon. All three labels contain elements of truth. But none (even in combination) perhaps is any longer sufficient to capture the whole.

\section{Brain Drain}

It is probably misleading to abandon this first label. Arguably it is still the most prominent feature of academic mobility, although with different degrees of intensity. 
There can be little doubt that there are winners and losers in terms of academic mobility. The winners, for the moment, are North America and Europe. Indeed, as has already been argued, American and European science have come to depend on the import of highly skilled academic talent from other countries - especially in some of the most dynamic disciplines. In a very real sense their university and research systems would no longer be scientifically sustainable if they had to rely on homegrown talent - which is a source of real concern. Because of other aspects of globalisation, too many perhaps of their most talented graduates have been attracted into finance, banking consultancy and similar occupations rather than continuing on to $\mathrm{PhDs}$ in science and technology. The impact of this loss of academic talent in 'exporting' countries, mainly those in the developing world, can be severe. For example, South Africa, to remedy the outflow to North America and Europe, must encourage an inflow from other poorer African countries. So global inequality is increased.

\section{Brain Gain}

But it is also possible to argue that all, or nearly all, higher education and research systems can benefit from academic mobility, albeit unevenly. Scientific research is a global domain, its results available everywhere. Indeed the growth of open-source publications of research findings (and the erosion of publishers' monopolies - and most of these publishers are based in North America or Europe) has reduced the barriers to accessing research findings. Similarly, the development of MOOCs may also reduce these barriers and inequalities of access. Mobile international academics are no longer so categorically 'lost' to the countries of their birth. They can now be 'present', if in a 'virtual form. Also, academic mobility enables scholars and scientists to gain new, radical and innovative, perspectives that can strengthen reform movements - as happened in the mid-20th century in the case of anti-colonial movements and liberation struggles. Containment of academic life within circumscribed (and easier-to-police) national environments can allow anti-liberal, and even authoritarian, ideas to survive more easily than in a more open, and international, intellectual domain.

\section{Brain Circulation}

This may also be a fair description of the effects of academic mobility - in several senses. First, the dominance of the 'West' - North America, Europe and their colonial/settler outposts - is being progressively eroded by the rise of universities in east and south Asia. Although currently this is mainly expressed in terms of shifting patterns of international student recruitment, it is reasonable to predict that in the future it will also be expressed in terms of academic mobility. The development of transnational education is also leading to the growth of more complex multi-linear patterns of academic development. The second sense in which it is right to talk of brain circulation is that advances in ICT and in the ease (and cost) of international travel have tended to weaken the case for long-term irreversible relocation. 
International academics can now more easily pursue hybrid careers, spending time in different countries.

There is another aspect of academic mobility that is sometimes overlooked - not simply the impact of such mobility on their countries of origin and their host countries (which is the primary focus of 'brain drain', 'brain gain' and 'brain circulation'); but also their impact on mobile academics themselves (which has been termed 'brain transformation'). This aspect of mobility has received considerable attention with regard to international students - and, indeed, is one of the most prominent perceived benefits of international student mobility. But it is equally, or even more significant, for mobile academic staff. ${ }^{15}$ Not only do such staff often create and maintain scientific capacity that might be unsustainable within national environments; they also are key carriers of scientific values, interpreters between different cultures. In key respects they may even be at the cutting edge of scientific innovation and intellectual novelty to a greater extent perhaps than their less mobile 'national' peers.

However, there is an argument that none of these labels offers a satisfactory interpretation of the effects of academic mobility, even in subtly balanced combination. The possibility should at least be considered that the terms and categories currently used to discuss academic mobility are out-of-date. It is possible to argue that, under 21 st-century conditions, the distinction between academics who make their careers at home and those who move to other countries may no longer be so sharp and meaningful as it was in the 20 th century. In the contemporary environment in which academic mobility can be regarded as just one element in global mobility, especially of elites, and also in which 'virtual' and 'physical' mobility are combined in curious and volatile mixtures, this binary distinction may have a reduced explanatory value. Maybe a better way to think about academic mobility is as a spectrum, from the deeply rooted to the highly mobile academic, with most strung somewhere along the middle of that spectrum. Nor should the less mobile academic be stigmatised as inferior, the implication of the weightings and criteria used in the construction of many global university league tables. It should always be remembered that Immanuel Kant never travelled far from his home in Königsberg (now Kaliningrad), just as it should also be recognised that the triviality of the jet-setting academic familiar in satiric 'campus' novels, always skating across the surface of academic life, is not always a caricature. In a very real sense all academics are now both 'local' and 'global'. To accept such a conclusion, of course, may undermine many of the studies of academic mobility, empirical or speculative, that rely on holding fast to these distinctions. But it also leans towards 'fluid globalisation' rather than 'hegemonic internationalisation' as a better framework in which to consider the future of academic mobility - and, as such, to regard such mobility in terms of hope rather than of threat.

\section{References and Notes}

1. N. Howard (2014) The transforming power of metaphor. http://www.open democracy.net/transformation/neil-howard/transforming-power-of-metaphor

2. H. Teekens (ed.) (2013) Global Education: A Narrative (The Hague: NUFFIC, Netherlands Organisation for International Cooperation in Higher Education). 
3. U. Teichler, I. Ferencz and B. Waechter (2013) Mapping Mobility in European Higher Education (Bonn: DAAD, German Academic Exchange Service).

4. T. Pietsch (2010) Wandering scholars? Academic mobility and the British World, 1850-1940. Journal of Historical Geography, 36, pp. 377-387.

5. P. G. Altbach and J. Knight (2007) The internationalization of higher education: Motivations and realities. Journal of Studies in International Education, 11(3-4), pp. 290-305.

6. T. Kim (2009) Shifting patterns of transnational academic mobility: a comparative and historical approach. Comparative Education, 45, p. 3.

7. Organisation for Economic Cooperation and Development (2013) Education Database: Foreign / International Students Enrolled (Paris: OECD Education Statistics) doi: 10.1787/data-00205-en, Paris: www.oecd.lib.org

8. United Nations Educational, Scientific and Cultural Organisation (2013) Table 17: Inbound mobility rates, female participation and sums of internationally mobile students. Table 18A: International flows of mobile students at the tertiary level. Table 18B: Outbound mobile students (students from a given country studying abroad), outbound mobility ratios and gross outbound mobility (Paris: Unesco Institute of Statistics), www.stats.uis.unesco.org

9. E. Hazelkorn (2011) Rankings and the Reshaping of Higher Education: The Battle for World-Class Excellence (London: Palgrave Macmillan).

10. C. Musselin (2004) Towards a European academic labour market? Some lessons drawn from empirical studies on academic mobility. Higher Education, 48, pp. $55-74$.

11. Z. Bauman (2000) Liquid Modernity (Cambridge: Polity Press).

12. J. Urry (2007) Mobilities (Cambridge: Polity Press).

13. J. Urry (2007) Global complexities. In: I. Rossi (ed.), Frameworks of Globalization Research (New York: Springer).

14. H. Nowotny (1996) Time: Modern and Postmodern Experience (Cambridge: Polity Press).

15. T. Kim (2010) Transnational academic mobility, knowledge and identity capital. Discourse: Studies in the Cultural Politics of Education (Special Issue on International Academic Mobility), 31(5), pp. 577-592.

\section{About the Author}

Peter Scott is Professor of Higher Education Studies at the UCL Institute of Education. Formerly he was Vice-Chancellor of Kingston University, also in London, and was for many years a journalist acting as Editor of The Times Higher Education Supplement for 16 years. From 2000 to 2008 he was President of the Academic Cooperation Association, the Brussels-based organisation that brings together national agencies concerned with international education. 